\title{
Mechanical and Bonding Behaviors Behind Bending Mechanism of Kaolinite Clay Layers
}

\author{
Daniel Tunega ${ }^{\S, *, *}$ and Ali Zaouil,**
}

$\S$ Institute for Soil Research, University of Natural Resources and Life Sciences, Peter-JordanStrasse 82, Wien A-1190, Austria

$\$$ School of Pharmaceutical Science and Technology, Tianjin University, Tianjin 300072, People’s Republic of China

" University Lille, IMT Lille Douai, University Artois, Yncrea Hauts-de-France, ULR 4515 LGCgE, Laboratoire de Génie Civil et géo-Environnement, F-59000 Lille, France

\section{Calculation of bending force constant, $k$.}

The bending force constant of kaolinite stripe model was obtained from the second derivative of bending energy, $E_{\mathrm{b}}$, as a function of deflection $(z)$, according equation (1)

$$
E_{b}=\frac{k}{2 l w} z^{2}
$$

$E_{\mathrm{b}}$ is expressed in $\mathrm{mJ} / \mathrm{m}^{2}$ and is obtained as $E_{\mathrm{b}}=E_{\mathrm{rel}} / A . A$ is an area of the periodic stripe model ( $A=l p, l$ is a width and $p$ is a periodicity of the of the stripe). Table $\mathrm{S} 1$ collects $l$ and $p$ parameters for the stripes of A and B type used in the calculations. The parameter $w$ in Eq. 1 is a thickness of the stripe models of the kaolinite layer having a value of $0.534 \mathrm{~nm}$. The deflection $z$ in Eq. 1 was obtained as $z=2 l^{2} /\left(16 R_{\mathrm{C}^{-}}\right)$, where $R_{\mathrm{C}}$ is a radius of curvature. The force constants for the opposite bending of the stripes A and B were obtained from the fitting of the quadratic function. The results of the fitting are shown in Fig. S1. The fitting was performed for a range $0.0-0.3 \mathrm{~nm}$ of the deflection $z$.

Table S1. Geometrical parameters of the stripes of A and B type.

\begin{tabular}{|l|l|l|}
\hline Stripe model & $l / \mathrm{nm}$ & $p / \mathrm{nm}$ \\
\hline A & 2.880 & 0.9049 \\
\hline $\mathrm{B}$ & 2.711 & 0.5214 \\
\hline
\end{tabular}




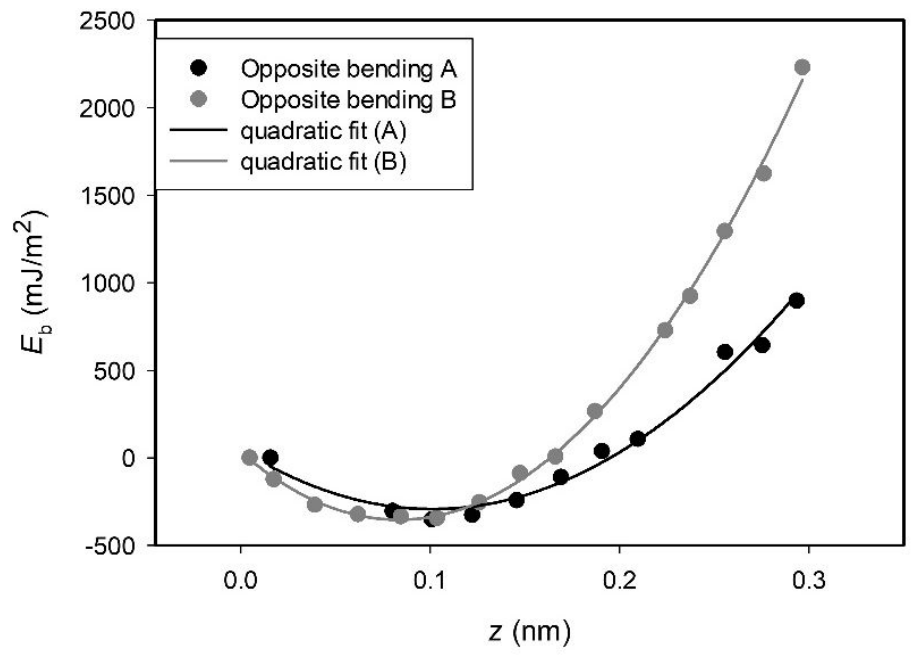

Figure S1. Fitting of quadratic function to calculated bending energy of opposite bending of A and $\mathrm{B}$ stripes.

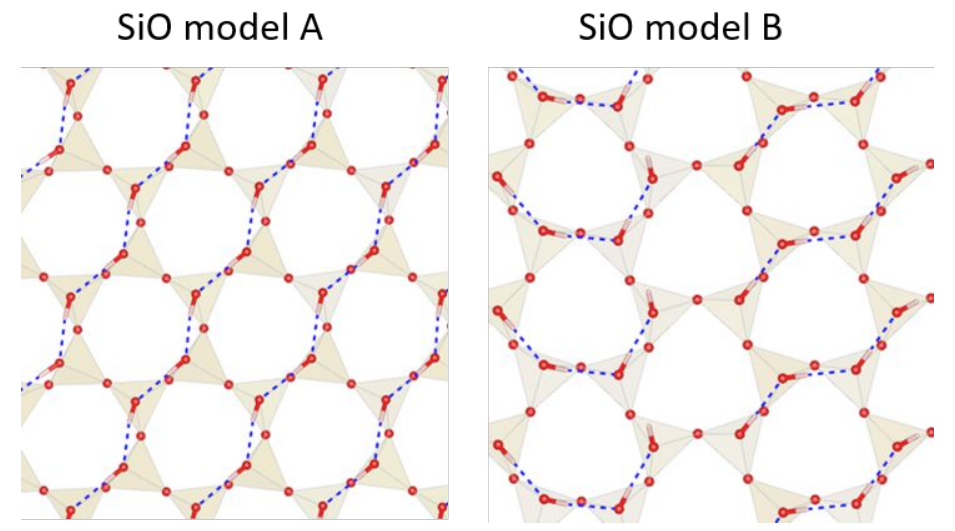

Figure S2. Hydrogen bond network of the SiO stripes. 


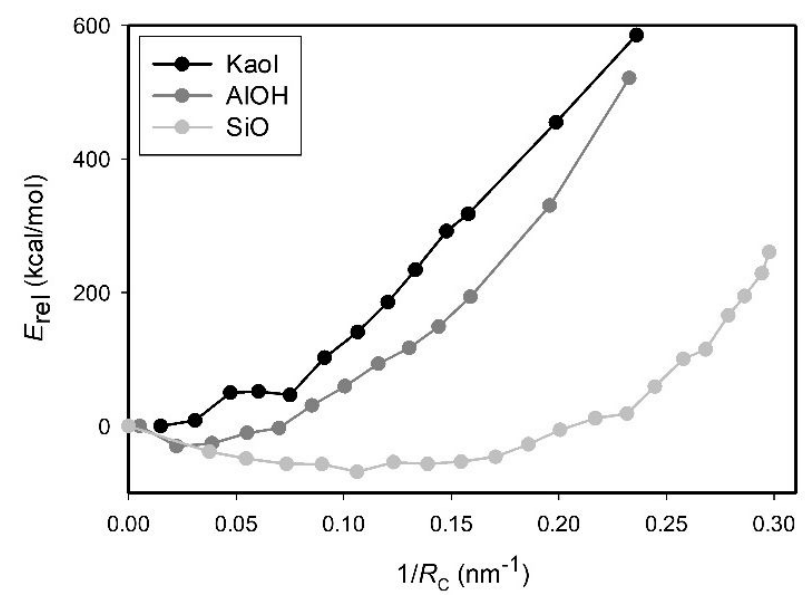

Figure S3. SiO, $\mathrm{AlOH}$, and kaolinite bending of the A type. 